\title{
Distensión de la vesícula biliar por obstrucción tumoral coledociana (signo de Courvoisier)
}

\author{
J. García-Cano, C. Jimeno, M. Viñuelas, N. Sánchez-Manjavacas y C. J. Gómez Ruiz
}

Sección de Aparato Digestivo. Hospital Virgen de la Luz. Cuenca

Un paciente de 77 años acudió a Urgencias por dolor abdominal, ictericia y coluria. En la exploración abdominal se palpó en el hipocondrio derecho una masa de consistencia blanda, levemente dolorosa y móvil. Este hallazgo correspondía, en una ecografía abdominal transcutánea, a una vesícula biliar hidrópica, alitiásica, con incipiente edema de pared (Fig. 1), secundaria a una obstrucción del flujo biliar causado por una masa de 4,8 x 2,8 cm en la cabeza de páncreas compatible con una neoplasia. La distensión de la vesicula biliar por obstrucción tumoral distal del colédoco es conocida como signo de Courvoisier (1). Ante el riesgo de rotura de la pared vesicular, se realizó una CPRE con intención de desobstruir la vía biliar. En la intervención endoscópica (Fig. 2) se observó una estenosis tanto del Wirsung como del colédoco. Se inyectó la mínima cantidad posible de contraste para no distender aún más la vesícula. Se realizó citología pancreática y se insertó una prótesis biliar metálica autoexpandible (Wallstent) no recubierta (Fig. 3). A las pocas horas el paciente mejoró clínicamente, remitiendo el dolor abdominal. En una resonancia nuclear magnética realizada al día siguiente (Fig. 4) la vesícula presentaba un tamaño grande, pero los signos del hidrops habían desaparecido. El Wallstent biliar no artefactó la exporación radiológica. Desde hace varias décadas, la endoscopia biliar (CPRE) es el método de elección para resolver, al menos inicialmente, la obstrucción coledociana $(2,3)$.

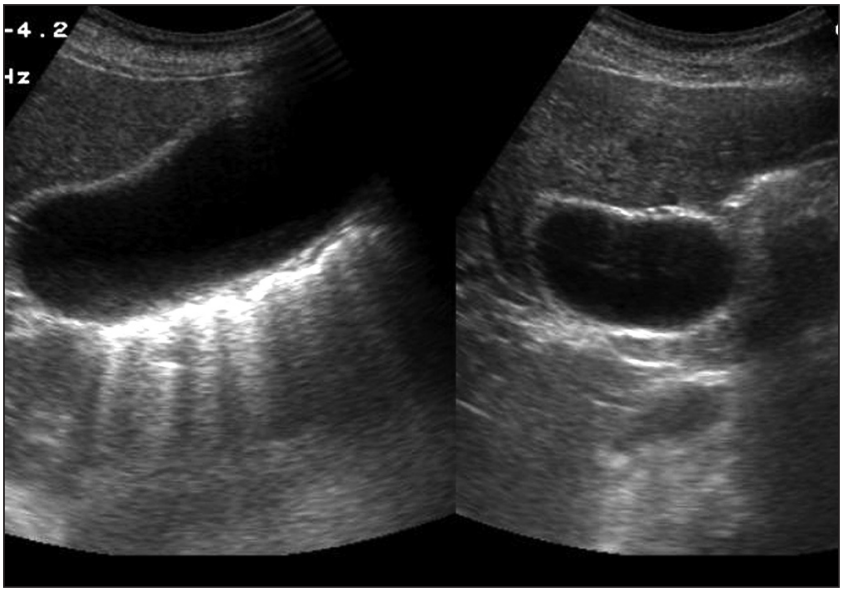

Fig. 1. Ultrasonografía transcutánea de la vesícula biliar. Corte sagital a la izquierda y transversal a la derecha. Se observa una distensión hidrópica de la vesícula con incipiente edema de pared, secundaria a una neoplasia de la cabeza del páncreas. A este signo se le conoce como de Courvoisier

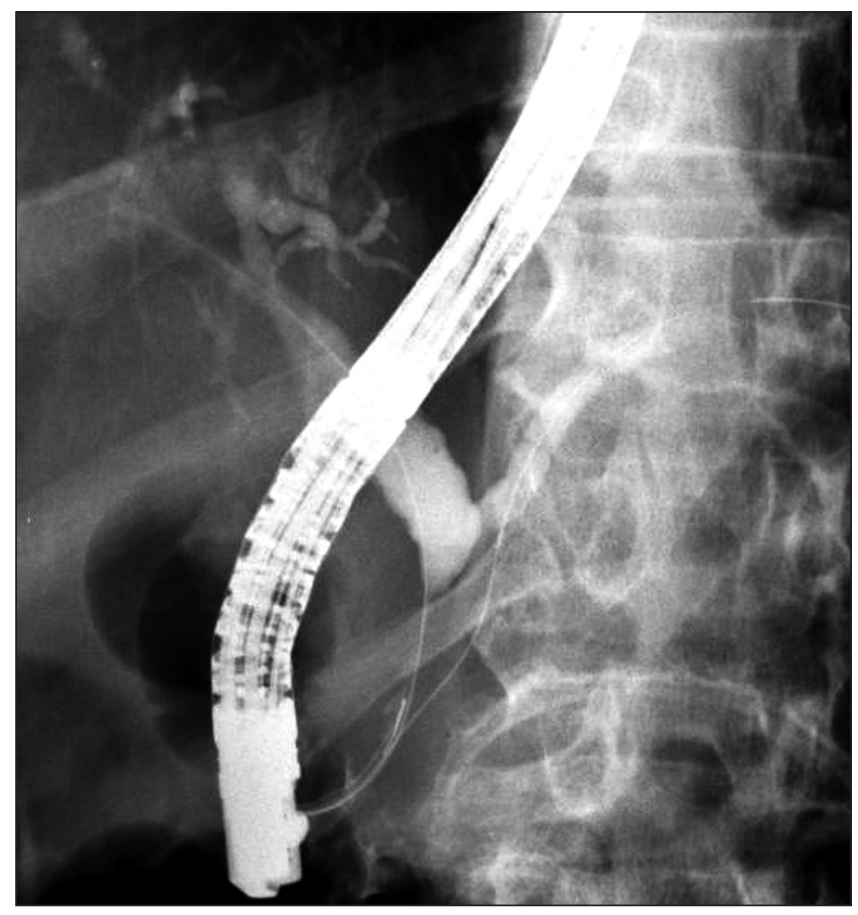

Fig. 2. Estenosis en el colédoco y Wirsung distales por una masa en la cabeza pancreática. Se ha insertado una guía en ambos conductos. 


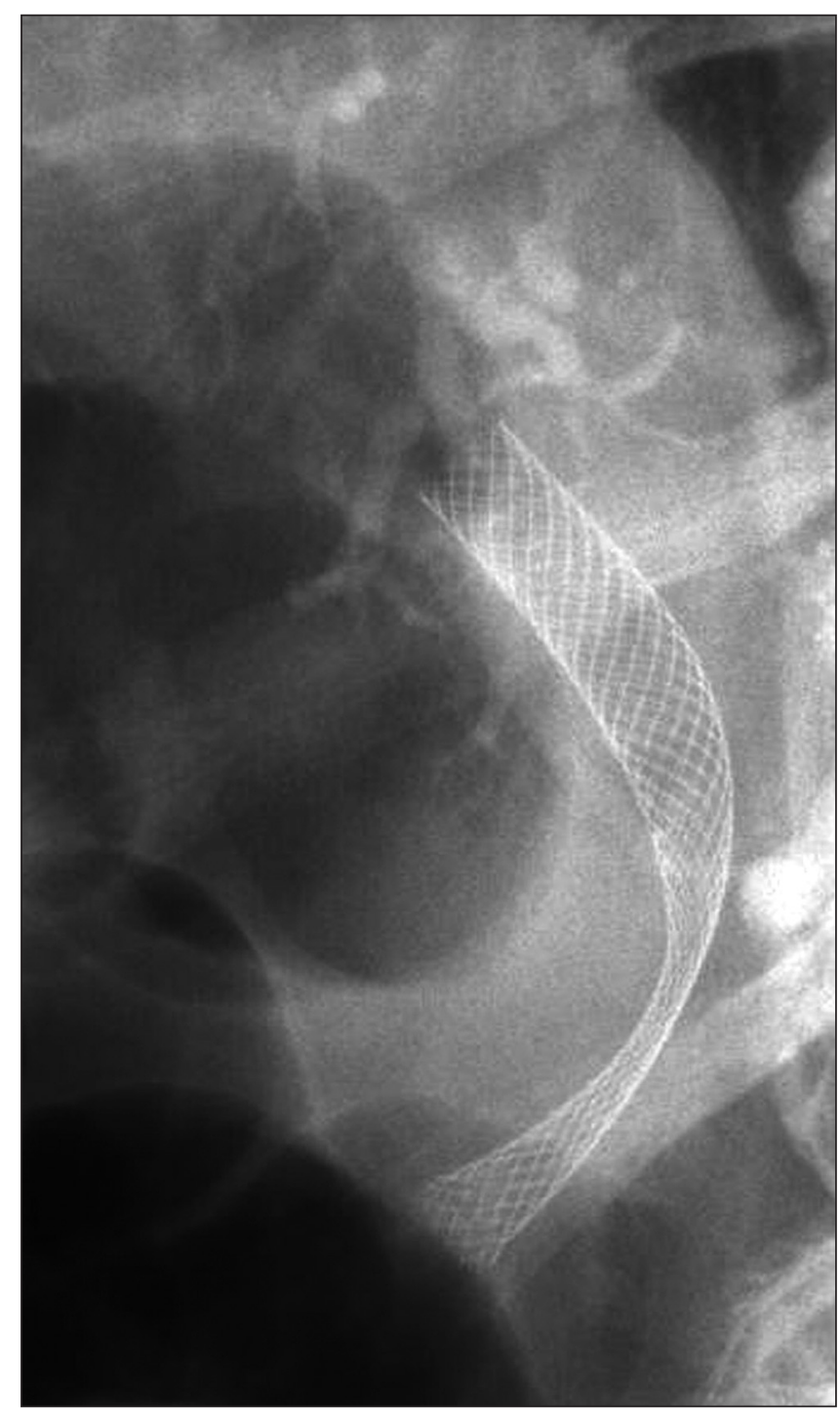

Fig. 3. Prótesis metálica autoexpandible biliar inmediatamente tras su colocación. Se observa la compresión del tumor en la zona distal.

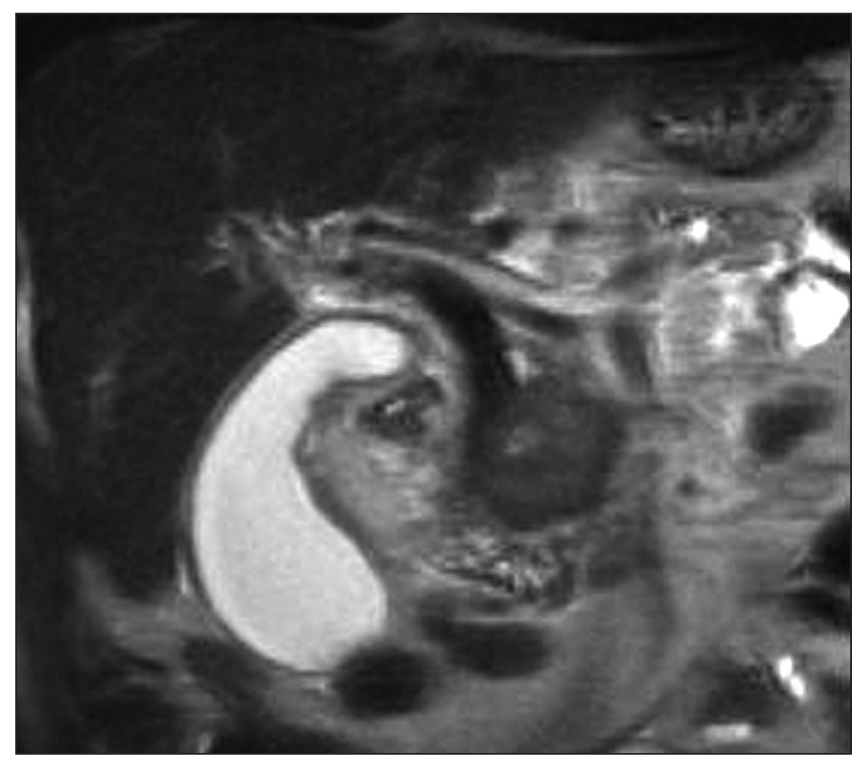

Fig. 4. Resonancia nuclear magnética tras el drenaje endoscópico biliar. La vesícula biliar tiene un tamaño grande pero no está distendida.

\section{BIBLIOGRAFÍA}

1. Noguer-Ballcels. Exploración clínica práctica. Masson, 2005

2. Summerfield JA. Biliary obstruction is best managed by endoscopists. Gut 1988; 29: 741-5.

3. García-Cano Lizcano J, González Martín JA, Pérez Sola A, Morillas Ariño J. Tratamiento endoscópico de la ictericia obstructiva en un hospital de nivel II del Sistema Nacional de Salud. Gastroenterol Hepatol 2001; 24: 287-91. 